\title{
Opportunistic salpingectomy for prevention of sporadic ovarian cancer - a jump from basic science to clinical practice?
}

\author{
Alicja Ziętek ${ }^{1}$, Michał Bogusiewiczz ${ }^{1}$ Justyna Szumiło' ${ }^{2}$, Tomasz Rech berger ${ }^{1}$ \\ ${ }^{1} 2^{\text {nd }}$ Department of Gynaecology, Medical University in Lublin, Poland \\ ${ }^{2}$ Department of Pathology, Medical University in Lublin, Poland
}

\begin{abstract}
Ovarian cancer is the most malignant and aggressive gynecological cancer. Due to nonspecific symptoms in the early stage and a lack of effective screening methods, it is typically diagnosed at an advanced stage. The high-grade serous cancer (HGSC) represents $75 \%$ of all ovarian cancers and accounts for the majority of deaths. Contemporary thought suggests that precursor lesions of HGSC originate in the fallopian tube. The presumed precursor tubal lesion, localized at the fimbrial end of the fallopian tubes, is termed the serous tubal intraepithelial carcinoma (STIC). Thus, removal of the fallopian tubes at the time of pelvic or abdominal surgery for a benign condition (i.e. opportunistic salpingectomy) appears as an attractive option for primary prevention of HGSC. This paper presents the scientific background of opportunistic salpingectomy and discusses controversies regarding the benefits and safety of the procedure.
\end{abstract}

Key words: fallopian tubes, ovary neoplasms, salpingectomy

Ginekologia Polska 2016; 87, 6: 467-472

\section{INTRODUCTION}

Ovarian cancer is the seventh most common malignancy in women worldwide and the second most common gynecological malignancy in developed countries. Each year there are approximately 230000 new cases diagnosed and about 140000 patients die due to ovarian cancer worldwide [1]. In Poland, in the year 2010 there were 3557 new registered cases of ovarian cancer. According to the prognosis of the Polish Union of Oncology for the year 2025, primarily due to aging of the population, the morbidity and mortality rates in ovarian cancer are expected to increase by $0.7 \%$ annually, with around 3800 new cases anticipated in the year 2025.

Ovarian cancer is the most lethal gynecological malignancy. Nonspecific symptoms in early stage of disease and a lack of effective screening methods are the main reasons why more than $70 \%$ of cases are diagnosed in FIGO stage III or IV. Despite the progress in therapy the mortality rate remains high with a five-year overall survival of only $20-40 \%$ for advanced disease [2, 3].
Recent histopathological, molecular and genetic studies resulted in recognition of dualistic model of carcinogenesis, which distinguish two broad categories of epithelial ovarian cancer (EOC): low-grade (type I) and high-grade (type II) tumors. These two types differ significantly in terms of clinical behavior, genetic and molecular background as well as precursor lesions.

The most common histological subtype among type II tumors is the high-grade serous cancer (HGSC), which represents $75 \%$ of all ovarian cancers and accounts for the majority of deaths [4]. According to contemporary thought, precursor lesions of HGSC originate in the fallopian tube fimbria. In recent years, removal of the fallopian tubes at the time of pelvic or abdominal surgery for a benign condition (i.e. opportunistic salpingectomy) appeared as an attractive option for primary prevention of HGSC. The paper presents the scientific background of opportunistic salpingectomy and discusses controversies regarding the benefits and safety of the procedure. 


\section{THE FALLOPIAN TUBE AS THE ORIGIN OF HIGH-GRADE SEROUS OVARIAN CANCER}

It is hypothesized that the junction of the fallopian tube epithelium with the ovarian mesothelium might be a potential site of carcinogenesis, similar to the uterine, cervical, gastroesophageal or anorectal junctions. Exposure of the fimbrial end to the locally elevated inflammatory cytokines at ovulation may trigger development of precursor lesions and malignant transformation by selection of $p 53$ mutations in epithelial cells, which are clonally stimulated to expand [5-7]. In turn, telomere shortening occurs and enhances the basal epithelium for transformation and development of dysplasia. Shortening of telomeres is one of the earliest molecular alterations in carcinogenesis observed in many human pre-invasive epithelial lesions [8].

The initial evidence for the fallopian origin of ovarian cancer came from the studies of prophylactic salpingo-oophorectomy in women bearing BRCA mutations. Detailed examination of fallopian specimens revealed dysplastic lesions, later designated as serous tubal intraepithelial carcinoma (STIC) located in the fimbrial end. The prevalence of STIC in asymptomatic BRCA mutation carriers is estimated to be between $2 \%$ and $6 \%[9,10]$.

It is worth emphasizing that precursor lesions have never been found in the ovarian epithelium.

The hypothesis that epithelial ovarian cancer originates from epithelium of the fallopian tubes is based on the logical sequence of events. P53 mutations are regarded as the earliest alterations that lead to formation of clusters of at least $12 \mathrm{se-}$ cretory cells with intense p53 immunoexpression and low proliferation index in morphologically normal fallopian tubes known as 'p53 signatures' [11]. These lesions, which can be identified histologically, were termed STIC [7, 12].

STIC is composed of non-ciliated (secretory) cells of the endosalpinx, which demonstrate characteristic features such as: variable combination of epithelial stratification (including loss of cellular polarity and exfoliation of cells into the lumen), intraepithelial fracture lines, irregular luminal surface, cellular pleomorphism, irregular chromatin pattern, nuclear rounding and molding, increased nuclear-to-cytoplasmic ratio, mitotic figures, and apoptotic bodies without evidence of any stromal invasion [13, 14].

HGSC,'p53 signatures' and STIC share identical p53 mutations suggesting a link between precursor lesions and carcinoma. Mucosal tubal involvement, including STIC, was observed in over $70 \%$ of cases of ovarian and primary peritoneal HGSC [15].

Recently, another potential precursor lesion, termed secretory cell outgrowths (SCOUTs), have been identified. They were described as a succession of at least 30 epithelial cells with a pseudostratified appearance [16]. SCOUTs do not bear p53 mutations, however, it is speculated that they act as a "precursor correlate" inducing alterations in p53-expressing benign lesions [7, 9].

There is growing evidence supporting the concept of the fallopian origin of ovarian HGSC. For instance, the gene expression profile of HGSC is closely related to fallopian tube epithelium rather than to the ovarian surface epithelium $[17,18]$. HGSC express a mesothelial marker — PAX8 — but not claritin, a mesothelial marker typical for ovarian surface [5]. Moreover, a clonal relationship between STIC and concomitant HGSC can be proved by the presence of identical p53 mutations and co-expression of p16, FAS, Rsf-1 and cyclin E1 [19]. Finally, a study on a mouse model showed that the removal of the fallopian tubes, but not removal of the ovaries, prevents HGSC formation $[9,20,21]$.

The precise mechanism of fallopian cell implantation into the ovary remains to be elucidated. It is likely that rupture of the dominant follicle at the time of ovulation exposes the underlying ovarian stroma to fimbrial epithelium. Thus, the progenitor lesions may implant on the ovarian surface or invaginate into the ovarian stroma [5-7,10, 22-25].

The detection rate of fallopian precursor lesions can be increased by detailed examination of the fimbrial end. To address this issue a protocol for Sectioning and Extensively Examining the FIMbria (SEE-FIM protocol) has been developed. In the first step, the distal $2 \mathrm{~cm}$ of fimbrial end is transected and then sectioned longitudinally in as many sections as practical. Finally, the remaining part of the tube is sectioned with $2-3 \mathrm{~mm}$ intervals and combined with the sectioned fimbrial end [25].

\section{ENDOMETRIOSIS AS A PRECURSOR LESION FOR TYPE I ENDOMETRIOID AND CLEAR CELL OVARIAN CARCINOMA}

Several epidemiological and molecular studies imply a link between endometriosis and low-grade endometrioid and clear cell ovarian carcinoma. A meta-analysis conducted by Kumar et al. showed that endometriosis increases overall ovarian cancer risk, but endometriosis-associated cancers are characterized by early-stage, low-grade and endometrioid or clear cell histology [26]. Similarly Pearce et al. performed an analysis of 13 studies and found that self-reported endometriosis is associated with an increased risk of clear-cell (Odds ratio (OR) 3.05) and endometrial (OR 2.21) ovarian cancer. Endometriosis associated ovarian cancer (EAOC) is defined as a type of neoplasm that coincides with endometriosis in the same or in the contralateral ovary, or with coexisting pelvic endometriosis. It was estimated that coincidence of endometriosis and carcinoma in the same ovary occurs in $35.9 \%$ of cases for clear cell and 19\% of cases for endometrioid type cancer [27-29]. Although there is no uniform theory of endometriosis pathogenesis, retrograde menstruation is likely to account for develop- 
ment of most cases. Consequently, endometrioid and clear cell ovarian carcinoma seem to arise from endometrial tissue implanted on the ovary. This hypothesis is supported by observations that tubal ligation decreases the risk of ovarian cancer, but only in cases of endometrioid and clear cell types [6, 30-32].

\section{OPPORTUNISTIC SALPINGECTOMY AS A PRIMARY PREVENTION STRATEGY}

Given the accumulating evidence indicating that serous, endometrioid and clear cell epithelial ovarian carcinomas do not originate directly from the ovary, salpingectomy performed at the time of pelvic or abdominal surgery for benign condition is an attractive option for primary prevention of ovarian malignancies. Presumably, this procedure may also prevent the development of mucinous and Brenner ovarian cancer, the pathogenesis of which has been linked to remnants of paratubal cysts (or Walthard cell nests) and primary fallopian tube cancer $[6,7]$. Additional benefits of salpingectomy may include prevention of tubal pathologies such as pyosalpinx or hydrosalpinx formation [33, 34]. Several scientific societies and opinion boards advocate consideration of the removal of the fallopian tubes during hysterectomy or other pelvic surgery in women who accomplished reproduction, where there is surgical access. Although, the fimbria is the preferred site, precancerous lesions have also been identified in the ampulla [20]. Therefore, the whole tube should be removed, if possible.

To date, there are no prospective studies evaluating the efficacy of opportunistic salpingectomy, thus a potential reduction in the incidence of epithelial ovarian carcinoma and related healthcare benefits are based on theoretical knowledge alone. Kwon et al., using the Monte Carlo simulation model, calculated that salpingectomy added to hysterectomy would reduce the ovarian cancer risk by $38.1 \%$ and when performed instead of tubal ligation by $29.2 \%$. However, the absolute benefit may be less evident since the number of cases of ovarian cancer among hysterectomized women would decrease from 270 to 167 cases per year [35]. A population-based study from Sweden showed a statistically significant 35\% lower risk for ovarian cancer among women with previous salpingectomy when compared to the unexposed population [36]. Less optimistic estimations have been derived for the German population, based on the assumption that all serous carcinomas originate from the fallopian tube and all hysterectomies would be combined with bilateral salpingectomy; this analysis predicted a reduction in the incidence of all ovarian cancers by only $2.3 \%$ over a period of 20 years [37]. A recent meta-analysis revealed that bilateral salpingectomy could reduce the risk of ovarian cancer by half $(O R, 0.51)$ in the general population. However, taking into account that only 29 out of 3509 pa- tients in the salpingectomy group developed cancer, the real number of women who may benefit from the procedure is low [38]. On the other hand, human papillomavirus (HPV) vaccination, which is generally accepted as a primary prevention of cervical cancer, requires exposure of 324 women to avoid one case of malignancy [39].

Salpingectomy appears safer and less harmful than salpingo-oophorectomy (SO). Removal of the ovaries before the age of 65 years is thought to increase the risk of cardiovascular disease, osteoporosis or cognitive impairment [40-43].

Opportunistic salpingectomy is not associated with significant perioperative risks. The average additional operating time required for salpingectomy was 16 minutes when added to hysterectomy, and 10 minutes when done instead of tubal ligation. Although statistically significant, these differences are of a little clinical significance. There is no increased risk of blood transfusion, prolonged hospitalization or rate of hospital readmission associated with salpingectomy. Similarly Minig et al. and Morelli et al. demonstrated that when salpingectomy was added to laparoscopic hysterectomy, there was no difference in operating time, postoperative hemoglobin, hospital stay, or complication rates. Even wide salpingectomy with excision of the mesosalpinx did not alter the perioperative blood loss, postoperative vital signs and patients' subsequent activities [39-42]. Chene et al. showed that salpingectomy could be safely performed in most (73.9\%) patients undergoing vaginal hysterectomy. There was only one case of postoperative hemorrhage among 51 patients after salpingectomy. Of interest, the prevalence of immunohistochemical abnormalities in the $\mathrm{p} 53$ protein phenotype in the removed tubes reached $12.9 \%$.

\section{DOES SALPINGECTOMY INFLUENCE OVARIAN FUNCTION?}

It is unlikely that salpingectomy negatively affects ovarian function. In animal models salpingectomy conducted simultaneously with hysterectomy did not alter ovarian volume, blood flow or follicle count. Morelli et al. showed that the addition of bilateral salpingectomy to total laparoscopic hysterectomy for prevention of ovarian cancer in women who do not carry a BRCA1/2 mutation did not impose negative effects on ovarian function. Serum concentrations of anti-Müllerian hormone (AMH) and follicle-stimulating hormone (FSH) remained stable shortly after tubal removal and in the 3-month follow-up period. No significant changes were observed in antral follicle count, ovarian diameter or peak systolic velocity [41-44]. In concert, Findley et al. confirmed a lack of detrimental effects associated with salpingectomy on AMH levels, even if surgical excision includes the removal of the mesosalpinx, the ovarian reserve is not damaged. Moreover, wide salpingectomy does not alter 
Table I. Statements of gynecological boards on opportunistic salpingectomy

\begin{tabular}{|c|c|}
\hline Board & Recommendation \\
\hline Royal College of Obstetricians and Gynaecologists [47] & $\begin{array}{l}\text { Women who are not at high risk for BRCA mutation and have } \\
\text { completed their families should be carefully considered for prophylactic } \\
\text { removal of the fallopian tubes with conservation of ovaries at the time } \\
\text { of gynaecological or other intraperitoneal surgery }\end{array}$ \\
\hline American College of Obstetricians and Gynecologists [48] & $\begin{array}{l}\text { The surgeon and patient should discuss the potential benefits of the } \\
\text { removal of the fallopian tubes during a hysterectomy in women at } \\
\text { population risk of ovarian cancer who are not having an oophorectomy } \\
\text { Prophylactic salpingectomy may offer clinicians the opportunity to } \\
\text { prevent ovarian cancer in their patients }\end{array}$ \\
\hline $\begin{array}{l}\text { Royal Australian and New Zealand College of Obstetricians and } \\
\text { Gynaecologists [49] }\end{array}$ & $\begin{array}{l}\text { Doctors should discuss the risks and benefits of bilateral salpingectomy } \\
\text { with patients undergoing hysterectomy for benign disease }\end{array}$ \\
\hline Society of Gynecologic Oncology [50] & $\begin{array}{l}\text { For women at average risk of ovarian cancer, risk-reducing } \\
\text { salpingectomy should also be discussed and considered with patients } \\
\text { at the time of abdominal or pelvic surgery, hysterectomy or in lieu of } \\
\text { tubal ligation }\end{array}$ \\
\hline Kommission Ovar of the AGO [50] & $\begin{array}{l}\text { During preoperative counselling prior to hysterectomy, all patients } \\
\text { should be informed about the potential beneficial impact of } \\
\text { opportunistic salpingectomy and the associated risks }\end{array}$ \\
\hline Committee on Gynecologic Practice [51] & $\begin{array}{l}\text { Current attempts at screening for ovarian cancer have been } \\
\text { unsuccessful and are associated with false-positive test results that } \\
\text { lead to unnecessary surgery and surgical complications. Prophylactic } \\
\text { salpingectomy may offer clinicians the opportunity to prevent } \\
\text { ovarian cancer in their patients. Randomized controlled trials are } \\
\text { needed to support the validity of this approach to reduce the incidence } \\
\text { of ovarian cancer }\end{array}$ \\
\hline
\end{tabular}
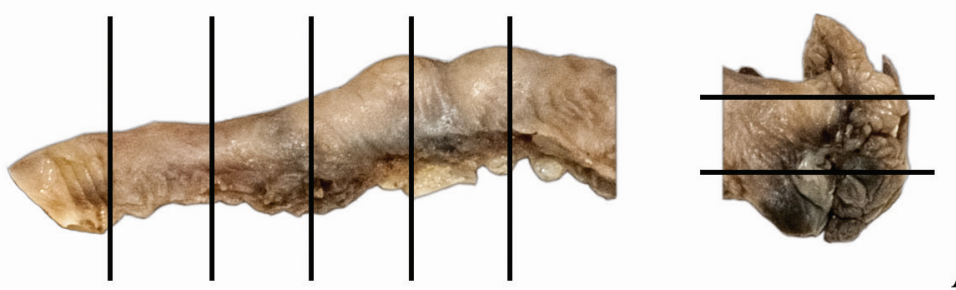

A
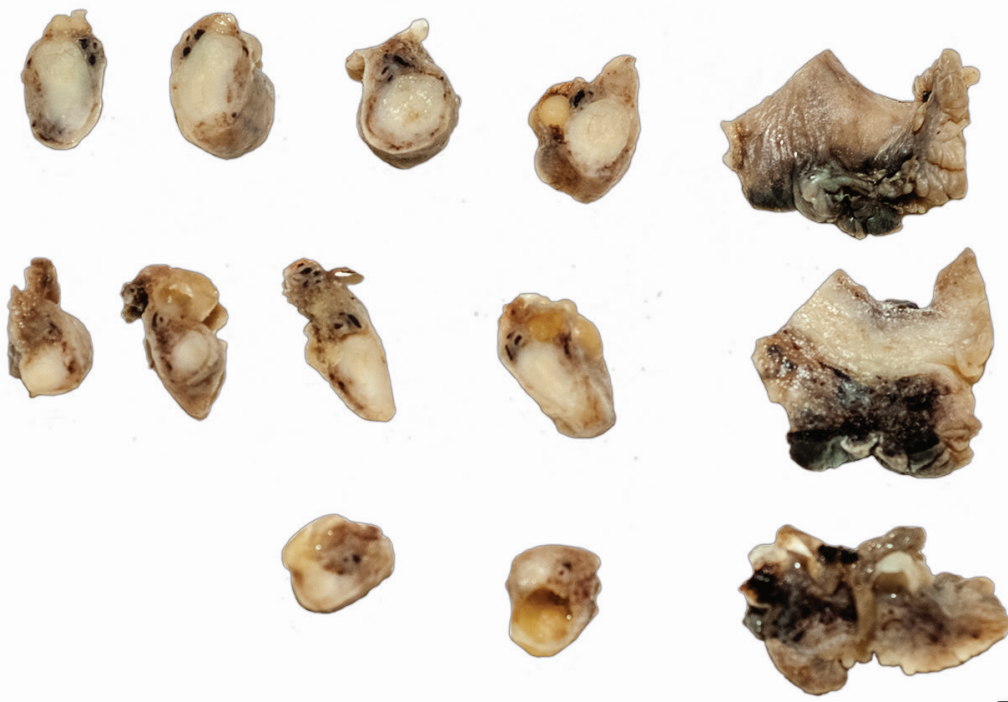

B

Figure 1. Fallopian tube specimen prepared by authors according to the protocol for Sectioning and Extensively Examining the FIMbria (SEE-FIM protocol). The directions of sections of the fimbrial end and remaining part of the tube are indicated on (A) 
blood loss during surgery, hospitalization stay or patients' return to normal activities $[45,46]$.

\section{CONCLUSION}

It has been described that opportunistic salpingectomy is a procedure of unproven efficacy. All data supporting the use of this procedure is derived from molecular, pathological and animal studies. Taken together, these data form the basis of a new theory or paradigm of ovarian cancer pathogenesis. The potential for randomized studies seems unrealistic and does not give the opportunity to resolve the issue for at least 20 years. On the other hand, salpingectomy performed at the time of other pelvic surgeries is a simple, costless procedure characterized by minimal, if any, morbidity. Many scientific societies and advisory boards recommend, or at least advocate, removal of fallopian tubes in women undergoing pelvic surgery who accomplished reproduction. Taking into account that high-grade serous ovarian cancer is a highly lethal disease, this procedure is worth considering as a potentially efficient preventive method.

\section{REFERENCES}

1. Torre LA, Bray F, Siegel RL, [et al.]. Global cancer statistics 2012. CA Cancer J Clin. 2015, 65 (2), 87-108.

2. Gallion HH, Bast RC Jr. National Cancer Institute Conference on Investigational Strategies for Detection and Intervention in Early Ovarian Cancer. Cancer Res. 1993, 53 (16), 3839-3842.

3. Didkowska J, Wojciechowska U, Zatoński W. Prognozy zachorowalności i umieralności na nowotwory złośliwe w Polsce do 2025 roku. www.puo. $\mathrm{pl} /$ publikacje/statystyki/prognozy-zachorowalnosci-i-umieralnoscina-nowotwory-zlosliwe-w-polsce-do-2025-roku (access: 2015.11.27).

4. Guth U, Huang DJ, Bauer G, [et al.]. Metastatic patterns at autopsy in patients with ovarian carcinoma. Cancer. 2007, 110 (6), 1272-1280.

5. Kurman RJ, Shih IM. The origin and pathogenesis of epithelial ovarian cancer: a proposed unifying theory. Am J Surg Pathol. 2010, 34 (3), 433-443.

6. Kurman RJ, Shih leM. Molecular pathogenesis and extraovarian origin of epithelial ovarian cancer-shifting the paradigm. Hum Pathol. 2011, 42 (7), 918-931.

7. Koshiyama M., Matsumura N, Konishi I. Recent concepts of ovarian carcinogenesis: type I and type II. Biomed Res Int. 2011, 42 (7), 918-931.

8. Gorgoulis WG, Vassiliou LV, Karakaidos P, [et al.]. Activation of the DNA damage checkpoint and genomic instability in human precancerous lesions. Nature. 2005, 434 (7035), 907-913.

9. Nowak-Markwitz E, Spaczyński M. Ovarian cancer-modern approach to its origin and histogenesis. Ginekol Pol. 2012, 83 (6), 454-457.

10. Longacre TA, Oliva E, Soslow RA, [et al.]. Recommendations for the reporting of fallopian tube neoplasms. Virchows Arch. 2007, 450 (1), 25-29.

11. Visvanathan K, Gross AL, Kurman RJ, [et al.]. Precursor lesions of high-grade serous ovarian carcinoma: morphological and molecular characteristics. J Oncol. 2010, 2010, 126295.

12. Mehrad M, Ning G, Chen EY, [et al.]. A pathologist's road map to benign, precancerous, and malignant intraepithelial proliferations in the fallopian tube. Adv Anat Pathol. 2010, 17 (5), 293-302.

13. Hu CY, Taymor ML, Hertig AT. Primary carcinoma of the fallopian tube. Am J Obstet Gynecol. 1950, 59 (1), 58-67.

14. Zweemer RP, van Diest PJ, Verheijen $\mathrm{RH}$, [et al.]. Molecular evidence linking primary cancer of the fallopian tube to BRCA1 germline mutations. Gynecol Oncol. 2000, 76 (1), 45-50.

15. Kindelberger DW, Lee Y, Miron A, [et al]. Intraepithelial carcinoma of the fimbria and pelvic serous carcinoma: Evidence for a causal relationship. Am J Surg Pathol. 2007, 31 (2), 161-169.

16. Chen EY, Mehra K, Mehrad M, [et al.]. Secretory cell outgrowth, PAX2 and serous carcinogenesis in the fallopian tube. J Pathol. 2010, 222 (1), 110-116.
17. Kurman RJ, Shih IM. Molecular pathogenesis and extraovarian origin of epithelial ovarian cancer-shifting the paradigm. Hum Pathol. 2011, 42 (7), 918-931.

18. Marquez RT, Baggerly KA, Patterson AP, [et al.]. Patterns of gene expression in different histotypes of epithelial ovarian cancer correlate with those in normal fallopian tube, endometrium, and colon. Clin Cancer Res. 2005, 11 (17), 6116-6126.

19. Sedhav AS, Kurman RJ, Kuhn E, [et al.]. Serous tubal intraepithelial carcinoma upregulates markers associated with high-grade serous carcinomas including Rsf-1 (HUBCAP), cyclin E and fatty acid synthase. Mod Pathol. 2010, 23 (6), 844-855.

20. Medeiros F, Muto MG, Lee A, [et al.]. The tubal fimbria is a preferred site for early adenocarcinoma in women with familial ovarian cancer syndrome. Am J Surg Pathol. 2006, 30 (2), 230-236.

21. Kim J, Coffey DM, Creighton CJ, [et al.]. High-grade serous ovarian cancer arises from fallopian tube in a mouse model. Proc Natl Acad Sci U S A. 2012, 109 (10), 3921-3926.

22. Vercellini $P$, Crosignani $P$, Somigliana $E$, [et al.]. The 'incessant menstruation' hypothesis: a mechanistic ovarian cancer model with implications for prevention. Hum Reprod. 2011, 26 (9), 2262-2273.

23. Suh DH, Lee $\mathrm{KH}, \mathrm{Kim} \mathrm{K}$, [et al.]. Major clinical research advances in gynecologic cancer in 2014. J Gynecol Oncol. 2015, 26 (2), 156-167.

24. Lancaster JM, Powell CB, Chen Lm, [et al.]. SGO Clinical Practice Committee. Society of Gynecologic Oncology statement on risk assessment for inherited gynecologic cancer predispositions. Gynecol Oncol. 2015, 136 (1), 3-7.

25. Crum CP, McKeon FD , Xian W. The oviduct and ovarian cancer: causality, clinical implications, and "targeted prevention". Clin Obstet Gynecol. 2012, 55 (1), 24-35.

26. Kumar S, Munkarah A, Arabi H. Prognostic analysis of ovarian cancer associated with endometriosis. Am J Obstet Gynecol. 2011, 204 (1), 1-7.

27. Wang S, Qiu L, Lang JH, [et al.]. Clinical analysis of ovarian epithelial carcinoma with coexisting pelvic endometriosis. Am J Obstet Gynecol. 2013, 208 (5), 413 e.1-e.5.

28. Lee AW, Templeman C, Stram Da, [et al.]. Evidence of a genetic link between endometriosis and ovarian cancer. Fertil Steril. 2015, 282 (1), 1940-1948.

29. Pearce CL, Templeman C, Rossing MA, [et al.]. Association between endometriosis and risk of histological subtypes of ovarian cancer: apooled analysis of caseecontrol studies. Lancet Oncol. 2012, 7 (4), 385-394.

30. Obata $\mathrm{K}$, Morland SJ, Watson $\mathrm{RH}$, [et al.]. Frequent PTEN/MMAC mutations in endometrioid but not serous or mucinous epithelial ovarian tumors. Cancer Research. 1998, 58 (10), 2095-2097.

31. Kato N, Sasou S, Motoyama T. Expression of hepatocyte nuclear factor- $1 \beta$ $(\mathrm{HNF}-1 \beta)$ in clear cell tumors and endometriosis of the ovary. Modern Pathol. 2006, 19 (1), 83-89.

32. Wiegand KC, Shah SP, Al-Agha OM, [et al.]. ARID1A mutations in endometriosis-associated ovarian carcinomas. New Eng J Med. 2010, 363 (16), 1532-1543.

33. Guldberg R, Wehberg S, Skovlund CW, [et al.]. Salpingectomy as standard at hysterectomy? A Danish cohort study, 1977-2010. BMJ Open. 2013, 3 (6), 1-5.

34. Farr R, Nezhat MD, Apostol R, [et al.]. New insights in the pathophysiology of ovarian cancer and implications for screening and prevention. Am J Obstet Gynecol. 2015, 213 (13), 262-267.

35. Kwon JS, McAlpine JN, Hanley GE, [et al.]. Costs and benefits of opportunistic salpingectomy as an ovarian cancer prevention strategy. Obstet Gynecol. 2015, 125 (2), 338-345.

36. Falconer $\mathrm{H}$, Yin $\mathrm{L}$, Grönberg $\mathrm{H}$, [et al.]. Ovarian cancer risk after salpingectomy: a nationwide population-based study. J Nat/ Cancer Inst. 2015, 107 (2), 1-6.

37. Pölcher M, Hauptmann S, Fotopoulou C, [et al.]. Opportunistic salpingectomies for the prevention of a high-grade serous carcinoma: a statement by the Kommission Ovar of the AGO. Arch Gynecol Obstet. 2015, 292 (1), 231-234.

38. Yoon SH, Kim SN, Shim SH, [et al.]. Bilateral salpingectomy can reduce the risk of ovarian cancer in the general population: A meta-analysis. Eur J Cancer. 2016, 55, 38-46.

39. Brisson $M$, Van de Velde $N$, De Wals $P$, [et al.]. Estimating the number needed to vaccinate to prevent diseases and death related to human papillomavirus infection. Can Med Assoc J. 2007, 177 (5), 464-468.

40. Parker WH, Broder MS, Chang E, [et al.]. Ovarian conservation at the time of hysterectomy and long-term health outcomes in the nurses' health study. Obstet Gynecol. 2009, 113 (5), 1027-1037. 
41. Kwon JS. Ovarian cancer risk reduction through opportunistic salpingectomy. J Gynecol Oncol. 2015, 26, 83-86.

42. Miller D, Finlayson S. BC's Ovarian Cancer Research Team. Advocating Fallopian Tube removal at the time of hysterectomy to prevent ovarian cancer. www.ovcare.ca/prevention/for_health_professionals

43. Minig L, Chuang L, Patrono MG, [et al.]. Surgical outcomes and complications of prophylactic salpingectomy at the time of benign hysterectomy in premenopausal women. J Minim Invasive Gynecol. 2015, 22 (4), 653-657.

44. Morelli M, Venturella R, Mocciaro R, [et al.]. Prophylactic salpingectomy in premenopausal low-risk women for ovarian cancer: primum non nocere. Gynecol Oncol. 2013, 129 (3), 448-451.

45. Findley AD, Siedhoff MT, Hobbs KA, [et al.]. Short-term effects of salpingectomy during laparoscopic hysterectomy on ovarian reserve: a pilot randomized controlled trial. Fertil Steril. 2013, 100 (6), 1704-1708.

46. Committee on Gynecologic Practice. Committee opinion no. 620: salpingectomy for ovarian cancer prevention. Obstet Gynecol. 2015, 125 (1), 279-281.
47. Royal College of Obstetricians and Gynaecologists .The Distal Fallopian Tube as the Origin of Non-Uterine Pelvic High-Grade Serous Carcinomas Scientific Impact Paper. 2014, 44, 1-8.

48. Salpingectomy for ovarian cancer prevention. Committee Opinion No. 620. American College of Obstetricians and Gynecologists. Obstet Gynecol. 2015, 125 (1), 279-281.

49. Brand AH. The RANZCOG College Statement on prophylactic oophorectomy in older women undergoing hysterectomy for benign disease: is the evidence sufficient to change practice? Aust N Z J Obstet Gynaecol. 2011, 51 (4), 296-300.

50. Pölcher M, Hauptmann S, Fotopoulou C, [et al.]. Opportunistic salpingectomies for the prevention of a high-grade serous carcinoma: a statement by the Kommission Ovar of the AGO. Arch Gynecol Obstet. 2015, 292 (1), 231-234.

51. Society of Gynecologic Oncology. SGO Clinical Practice Statement: Salpingectomy for Ovarian Cancer Prevention. 2013. www.sgo.org/clinicalpractice/guidelines/ sgo-clinical-practice-statement-salpingectomy-for-ovarian-cancerprevention 